\title{
A Novel Hybrid Moth Flame Optimization with Sequential Quadratic Programming Algorithm for Solving Economic Load Dispatch Problem
}

\author{
KASHIF REHMAN*, AND AFTAB AHMAD* \\ RECEIVED ON 06.11.2017 ACCEPTED ON 12.02.2018
}

\begin{abstract}
The insufficiency of energy resources, increased cost of generation and rising load demand necessitate optimized economic dispatch. The real world ED (Economic Dispatch) is highly non-convex, nonlinear and discontinuous problem with different equality and inequality constraints. In this research paper, a novel hybrid MFO-SQP(Moth Flame Optimization with Sequential Quadratic Programming) is proposed to solve the ED problem. The MFO is stochastic searching algorithm minimizes by random search and SQP is definite in nature that refines the local search in vicinity of local minima. Proposed technique has been implemented on 6,15 and 40 units test system with different constraints like valve point loading effect, transmission loss, prohibited zones, generator capacity limits and power balance. Results, obtained from proposed technique are compared with those of the techniques reported in the literature, are proven better in terms of fuel cost and convergence.
\end{abstract}

Key Words: Economic Dispatch, Prohibited Zones, Transmission Loss, Sequential Quadratic Programming.

\section{INTRODUCTION}

$\checkmark$ lectricity plays a vital role in the economy of any country and electrical power system has central importance in this regard. Power system has complex structure. Today researchers are demanding to make the generation of power system most economical and reliable. ED is a generation allocation problem, which assigns the real power to generator at lowest possible cost while satisfying all constraints. It is highly non-linear, non-convex and multi-constrained optimization problem. Limited energy sources, ever-growing energy demand and increased fuel cost makes ED a very important problem in present power system.
In past many conventional optimization techniques are implemented on ED problem. These techniques are based on derivatives. For example, $\lambda$-iteration and gradient methods [1] use first order derivatives. Classical techniques are not suitable for solving nonconvex ED problem due to local optimum entrapment and requirement of starting point for their working [2]. LP (Linear Programming) method [3] is found to be competent but it is limited to linear optimization problem only. DP (Dynamic Programming) has been used to solve the non-convex problem but it suffers from curse of

Authors E-Mil: (kashifrehman2015@gmail.com, aftab.ahmad@uettaxila.edu.pk)

* Department of Electrical Engineering, University of Engineering \& Technology, Taxila, Pakistan.

This is an open access article published by Mehran University Research Journal of Engineering and Technology, Jamshoro under the CC by 4.0 International License. 
dimensionality. AI (Artificial Intelligence) based techniques offer potential solution for solving the ED problem due to presence of non-linearity. To alleviate above mentioned drawbacks, a new algorithm was proposed which is named as GA (Genetic Algorithm) [4]. GA uses crossover and mutation and reproduces new population with improved fitness. GA has stochastic behavior in selection, mutation and reproduction, which make it more efficient and avoid local optimum stagnation problem. With the proposal of GA, this field got highest attention and well known algorithm like ACO (Ant Colony Optimization) [5], PSO (Particle Swarm Optimization) Algorithm [6], DE (Differential Evolution) [7], ES (Evolutionary Strategy) [8], EP (Evolutionary Programming) [9], SA (Simulated Annealing) [10] and their numerous alternatives have been developed.

Many techniques have been used for this purpose. Some of them are called evolutionary methods. Similarly, some are based on simple mathematical concept and some belong to the AI (Artificial Intelligence). Among these techniques few lag due to non-qualitative results, computational burden, premature convergence, bulk memory consumption, large number of control parameters, large time consumption, non-consistent performance, complex structure, failure for large problem, global and local optimum search space limitations. According to No Free Lunch theorem there is no best technique which can solve all optimization problems. Every optimization technique has some advantages as well as some drawbacks. There is always the need of new techniques, which can solve problem better than the current optimization techniques.

MFO algorithm is novel SI (Swarm Intelligence) technique developed by Mirjalili [11]. This SI algorithm is made by motivation from navigation method of moths. This technique has been implemented on ED problem. As compared to other techniques, MFO reaches near global optimum and less global searching ability especially for large scale. To overcome the abovementioned drawbacks, SQP is proposed to hybridize with the MFO. In the start MFO will run and explore the search space to get optimal solution. This optimal solution of MFO will become the starting point of SQP. SQP is used as local fine tune searcher for the search space explored by MFO. In this way, results obtained after SQP will be more refined. This hybrid algorithm is tested on 6,15 and 40 units systems and results are compared with those obtained by using different algorithms reported in the literature.

\section{PROBLEM FORMULATION}

ED is generally a minimization problem with different constraints. Mathematically there is an objective function that is total cost of generation supplied to the load. It is given by [12].

$F_{T}=\sum_{i}^{N} F_{i} P_{i}$

$\mathrm{F}_{\mathrm{t}}$ represents the total fuel cost of generation and $\mathrm{F}_{\mathrm{i}} \mathrm{P}_{\mathrm{i}}$ is the fuel cost of $\mathrm{i}^{\text {th }}$ generator and $\mathrm{P}_{\mathrm{i}}$ is the active power generation of $\mathrm{i}^{\text {th }}$ generator.

Objective function of ED problem has two types, convex and non-convex. Quadratic curve is used to represent the convex characteristics and modeled in [12].

$F_{i}\left(P_{i}\right)=a_{i} P_{i}^{2}+b_{i} P_{i}+c_{i}$

Practically, large generating units have multivalve operations which directly effect on the input/output curve

Mehran University Research Journal of Engineering \& Technology, Volume 38, No. 1, January, 2019 [p-ISSN: 0254-7821, e-ISSN: 2413-7219] 
of generator. This effect is called valve point loading effect. A sinusoidal term is added to the convex equation for the modeling of non-convex characteristic as:

$F_{i}\left(P_{i}\right)=a_{i} P_{i}^{2}+b_{i} P_{i}+c_{i}+\left|e_{i}+\sin \left(f\left(P_{i, \min }-P_{i}\right)\right)\right|$

$\mathrm{a}, \mathrm{b}$ and $\mathrm{c}$ are the cost coefficient, e and $\mathrm{f}$ are constants representing the valve point loading effect. Following are different constraints which are used to minimize ED problem

\subsection{Power Balance Constraint}

Real power balance constraint is given by Equation (4).

$P_{L}+P_{\text {loss }}=\sum_{i}^{N} P_{i}$

$\mathrm{P}_{\mathrm{L}}$ and $\mathrm{P}_{\text {loss }}$ are load and power loss and $\sum_{i}^{N} P_{i}$ is the total generation.

\subsection{Generator Limits}

Generation from generator must be in limits which is modeled as:

$\mathrm{P}_{\mathrm{i}, \min } \leq \mathrm{P}_{\mathrm{i}} \leq \mathrm{P}_{\mathrm{i}, \mathrm{mix}}$

$\mathrm{P}_{\mathrm{i}, \min }$ is the minimum power generation capacity and $\mathrm{P}_{\mathrm{i}, \max }$ is the maximum power generation capacity of generator.

\subsection{Transmission Loss}

Transmission loss in ED problem is calculated by using coefficient method which is described as follows:

$P_{\text {loss }}=\sum_{i}^{N} \sum_{i}^{N} P_{i} B_{i j} P_{j}+\sum_{i}^{N} B_{o i} P_{i}+B_{\infty}$

$\mathrm{B}_{\infty}$ is a constant, $\mathrm{B}_{\mathrm{oi}}$ is a vector which have dimension equal to $\mathrm{P}_{\mathrm{i}}$ and $\mathrm{B}_{\mathrm{ij}}$ represents the loss coefficient matrix.

\subsection{Prohibited Operated Zones}

There are regions in the generator output which are prohibited. Vibration is produced if generator is operated in that region which ultimately results into the damage. These zones are modeled as follows:

$$
\begin{aligned}
& P_{i, \min } \leq P_{i} \leq P_{i, 1} l \\
& P_{i, j-1^{u}} \leq P_{i} \leq P_{i, 1} l \\
& P_{i, m^{u}} \leq P_{i} \leq P_{i, \max }
\end{aligned}
$$

In Equation (7), $\mathrm{m}$ is represents the number of prohibited zones, $\mathrm{P}_{\mathrm{i}, \mathrm{j}-\mathrm{iu}}$ is the lower limit of $\mathrm{i}^{\text {th }}$ operating zone of $\mathrm{i}^{\text {th }}$ generator and $\mathrm{P}_{\mathrm{i}, \mathrm{mu}}$ is the upper limit of $\mathrm{i}^{\text {th }}$ operating zone of $i^{\text {th }}$ generator. All above constraints are presented in [12].

\section{MOTH FLAME OPTIMIZATION}

MFO is a novel SI technique developed by Mirjalili [11]. SI techniques are inspired from natural flocking of birds, insects, colonies of ants, school of fish like GWO (Grey Wolf Optimization) algorithm [12], PSO [6] etc. This algorithm is made by the inspiration of navigation method of moths. Moths can fly in all dimensions (one, two, three and hyper dimensional space) and have ability to change their position vectors. The main inspiration about moths is their navigation system named as transverse orientation. In this mechanism, moths fly over long distances without changing straight path by making fixed angle with distant light source (moon) in night. Moon is far away from earth so moths use it to fly in straight path.

From above discussion, transvers orientation mechanism is very efficient and an effective method to move in straight path. But in daily life experience, we observe that moths 
fly in spiral path instead of straight path around the light source. Moths are entrapped by artificial light source and start flying around it. Transverse orientation method is only effective when light source is far away [11]. Whenever moths see human made light source in their path and try to make that angle with artificial light source, they start flying in spiral path around that light source. Entrapment behavior of moths becomes inspiration for the authors, modeling that behavior mathematically to propose what is called MFO algorithm.

In every iteration, value of $t$ in the moths spiral equation is randomly generated which results into a new path for moth. So, moth will search better solution around the flame and try to update that position if they find better. During their searching process moths always retain best solution. To avoid local optimum each moth is updated with corresponding flame and after number of iterations all moth will update with best flame. In corresponding updating first moth is updated with best flame and last month is updated with worst flame. In proposed algorithm if position of moth lies outside the search space then exploration takes place.

In ED problem moths are the real powers of generators which will be generated randomly and flames are the sorted moths (real powers) according to their costs in increasing manner from top to bottom. MFO will optimize these flames by using its updating procedure and provide only one best flame at lowest cost which will be the solution of ED problem

\section{SEQUENTIAL QUADRATIC PROGRAMMING}

SQP search algorithm is extensively used for constrained optimization problems. It is robust and efficient than non- linear programming. In every iteration, it approximates the Hessian of Lagrangian function which constitute subquadratic problem to provide direction for linear line search. SQP requires local minima due to non-convex objective function. QP problem is solved in every iteration to update line search which is described in [13].

$\operatorname{Minimize} \nabla F\left(P_{k}\right)^{2} d_{K}+\frac{1}{2} d_{k}^{T} H_{K} d_{K}$

Subject to

$$
\begin{array}{lr}
g_{i}\left(P_{K}\right)+\left[\nabla g\left(P_{K}\right)\right]^{T} d_{K}=0 & i=1, \ldots, m_{e} \\
g_{i}\left(P_{K}\right)+\left[\nabla g\left(P_{K}\right)\right]^{T} d_{K} \leq 0 & i=m_{e}+1, \ldots, m
\end{array}
$$

In Equations (8-9) $\mathrm{H}_{\mathrm{K}}$ represents the Hessian matrix in the langrangian function, $\mathrm{d}_{\mathrm{K}}$ represents the direction search, $\mathrm{P}_{\mathrm{K}}$ represents the vector of real power and $\mathrm{g}_{\mathrm{i}}\left(\mathrm{P}_{\mathrm{K}}\right)$ are the equality and non-equality constraint in the Kth iteration. $\mathrm{m}_{\mathrm{e}}$ is the quantity of equality constraints and $\mathrm{m}$ is the quantity of constraints.

$\mathrm{L}(\mathrm{P}, \lambda)=\mathrm{F}(\mathrm{P})+\mathrm{g}(\mathrm{P})^{\mathrm{T}} \lambda$

$\lambda$ is the vector that represents the lagrangian multiplier and $\mathrm{H}_{\mathrm{K}}$ matrix is calculated by quasi-newton formulation

$\mathrm{H}_{\mathrm{K}+1}=H_{K}+\frac{q_{K} q_{K}^{T}}{q_{K}^{T} S_{K}}-\frac{H_{K}^{T} S_{K}^{T} H_{K}}{S_{K}^{T} H_{K} S_{K}}$

Where

$\mathrm{S}_{\mathrm{K}}=\mathrm{P}_{\mathrm{K}+1}-\mathrm{P}_{\mathrm{K}}$

$\mathrm{q}_{\mathrm{K}}=\nabla \mathrm{L}\left(\mathrm{P}_{\mathrm{K}+1}, \lambda_{\mathrm{K}+1}\right)-\nabla \mathrm{L}\left(\mathrm{P}_{\mathrm{K}}, \lambda_{\mathrm{K}+1}\right)$

In every iteration, sub-QP problem the direction $d_{K}$ is calculated and the solution found from the novel iterate as: 
$\mathrm{P}_{\mathrm{K}+1}+\mathrm{P}_{\mathrm{K}}-a_{\mathrm{K}} \mathrm{d}_{\mathrm{K}}$

For achieving a significant decrease in augmented lagrangian merit function the step length value $\alpha_{K}$ is determined.

$\mathrm{L}_{\mathrm{A}}(\mathrm{P}, \lambda, \rho)=\mathrm{F}(\mathrm{P})-\lambda^{T} g(P)+\frac{\rho}{2} g(P)^{T} g(P)$

\section{IMPLEMENTATION OF MFO-SQP ON ED PROBLEM}

Step-1: An initial random population containing generation allocation is generated by selecting the number of moths (search agents) in this step. Number of moths will determine the size of population. Matrix A is created which represents the moth population.

$A=\left(\begin{array}{ccc}a_{1}^{1} & \cdots & a_{n g}^{1} \\ \vdots & \ddots & \vdots \\ a_{1}^{n} & \cdots & a_{n g}^{n}\end{array}\right)$

Where $\mathrm{n}$ is the number of moths and $\mathrm{ng}$ is the number of dimensions.

There is an array OA which store fitness values of all moths.

$O A=\left[\begin{array}{c}a^{1} \\ a^{2} \\ \vdots \\ a^{n}\end{array}\right]$

Flames are the other component of MFO which are identical to moth matrix.

$B=\left(\begin{array}{ccc}b_{1}^{1} & \cdots & b_{n g}^{1} \\ \vdots & \ddots & \vdots \\ b_{1}^{n} & \cdots & b_{n g}^{n}\end{array}\right)$
Where $\mathrm{n}$ is the number of moths and $\mathrm{ng}$ is the number of dimensions and B shows the flames. Like moth fitness value there is also an array $\mathrm{OB}$ which store fitness values of flames.

$O B=\left[\begin{array}{c}b^{1} \\ b^{2} \\ \vdots \\ b^{n}\end{array}\right]$

Both moth and flames are the solutions. The difference between moths and flames are the way of updating them. Moths are treated as search agents and flames are positions of moths. Moths fly in the search space around the flames in spiral path and they are not restricted to space between moths and flames. This process of searching is very effective for exploitation and exploration.

Step-2: In second step fitness values of all moths are calculated using objective function ED problem.

Step-3: In this step iteration number is checked. If iteration number is one, then sort single moth population. Sorted moth population is assigned as flames. If iteration number is greater than one, then previous population will be taken in this iteration. In this way, double population will obtain in every iteration after the first iteration. To get double flames, double population of moths will be sorted and their fitness function is calculated.

Step-4: In this step updating procedure is applied to get new population of moths. First flame number is to be found by using following formula:

Flame_no $=\mathrm{N}-$ iter.no $\frac{\mathrm{N}-1}{\max . \text { iter }}$ 
$\mathrm{N}$ is maximum number of flames.

Case-1: If iteration number $<$ flame number then moths are update with respect to corresponding flames.

Case-1: If iteration number $>$ flame number then moths are update with flame one (means best solution)

After getting direction of updating, following equation is used to update the moths

Moth $_{\mathrm{i}}=\mathrm{S}\left(\right.$ Moth $_{\mathrm{i}}$, Flame $\left._{\mathrm{j}}\right)$

$\mathrm{S}$ is a spiral function which is defined as

$\mathrm{S}=\mathrm{D}_{\mathrm{i}} \cdot \mathrm{e}^{\mathrm{bt}} \cdot \cos 2 \pi \mathrm{t}+$ Flame $_{\mathrm{j}}$

Where

$\mathrm{D}_{\mathrm{j}}=\mid$ Flame $_{\mathrm{i}}-$ Moth $_{\mathrm{j}} \mid$

In spiral function $\mathrm{b}$ is a constant which defines the shape of spiral. In ED problem value of $b$ is taken 1 and $t$ is a random number. Following formula is used to calculatet.

$\mathrm{t}=(-1+a)$ random +1

In Equation (22) value of $a$ is called convergence constant which is linearly decreases from -2 to -1 .

$a=(-1+$ iter_no $) \frac{-1}{\max . \text { iter }}$

Step-5: Inequality and equality constraints are checked in this step. if inequality constraint such as generator capacity limits, prohibited operated zones are violated then fix them. Equality constraint is handled by using penalty.

Step-6: After reaching maximum iterations best position obtained through MFO will be used as starting point of
SQP. Now SQP optimize and produce best solution which will replace with the solution of MFO.

\section{CASE STUDIES AND RESULTS}

Proposed algorithm has been implemented on 6, 15 and 40 units standard test systems. Different constraints of thermal generators like power balance, transmission loss, generator capacity limits and prohibited zones are considered. Transmission loss is calculated by using B coefficient method. All simulations are performed in MATLAB R2015a core i3 processor. Following test cases are studied in this research work

Test Case-1: This is a 6 units convex test system with load demand of 1263 MW. Transmission loss and prohibited zones are considered in this system.

Test Case-2: This is a 15 units convex test system with load demand of 2630 MW. Transmission loss and prohibited operated zones are considered in this system.

Test Case-3: This is a 40 units non-convex test system with load demand of $10500 \mathrm{MW}$. Transmission loss is considered.

\subsection{Test System-1}

In this test system, proposed MFO technique has been implemented on 6 units test system with load demand of $1263 \mathrm{MW}$. This is a convex test system with transmission loss and prohibited operated zones are considered as constraints. Test system data consisting of generation limits and cost coefficients are taken from [14]. Transmission loss is calculated by using coefficient method. Numbers of moths are 30 for this test system with 300 iterations and 50 trails. 
Table 1 gives the optimal generation and total fuel cost from proposed technique. Total fuel cost found to be 15444.186 US\$/hr and loss calculated is $12.75 \mathrm{MW}$. Table 2 is showing statistical analysis of proposed technique with another like MTS, DE, PSO, GAAPI, KHA-1, KHA-2, MABC, CBA and MFO. Propose technique has saved the fuel cost from above mentioned techniques.
Fig. 1 is showing the convergence characteristics of MFOSQP at 300 iterations. Proposed algorithm converges to optimal point before reaching to stopping criteria.

\subsection{Test System-2}

In this system 15 units test system has taken with load demand of $2630 \mathrm{MW}$. For the sake of comparison convex

TABLE 1. OPTIMAL GENERATION AND COST (6 UNITS TEST SYSTEM)

\begin{tabular}{|c|c|c|c|c|}
\hline Units & $\begin{array}{c}\mathrm{P}_{\text {imin }} \\
(\mathrm{MW})\end{array}$ & $\begin{array}{c}\mathrm{P}_{\text {imax }} \\
(\mathrm{MW})\end{array}$ & $\begin{array}{c}\text { Generation } \\
(\mathrm{MW})\end{array}$ & $\begin{array}{c}\text { Fuel Cost } \\
\text { (US\$/hr) }\end{array}$ \\
\hline 1 & 100 & 500 & 446.715 & 4763.885 \\
\hline 2 & 50 & 200 & 173.149 & 2216.305 \\
\hline 3 & 80 & 300 & 262.795 & 3075.308 \\
\hline 4 & 50 & 150 & 143.490 & 1963.694 \\
\hline 5 & 50 & 200 & 163.917 & 2156.079 \\
\hline 6 & 50 & 120 & 85.356 & 1268.914 \\
\hline
\end{tabular}

TABLE2. COMPARISON OF 6 UNITS TEST SYSTEM

\begin{tabular}{|c|c|}
\hline Technique & $\begin{array}{c}\text { Best Cos } \\
\text { (US\$hr })\end{array}$ \\
\hline MTS [15] & 15450.060 \\
\hline DE [16] & 15449.766 \\
\hline PSO [17] & 15450.840 \\
\hline GAAPI [18] & 15607.470 \\
\hline KHA-1 [19] & 15450.000 \\
\hline KHA-2 [19] & 15448.211 \\
\hline KHA-3 [19] & 15445.356 \\
\hline VSA [20] & 15448.000 \\
\hline MABC [21] & 15449.899 \\
\hline CBA [22] & 15450.000 \\
\hline MFO [23] & 15448.723 \\
\hline Proposed MFO-SQP & 15444.187 \\
\hline
\end{tabular}

Mehran University Research Journal of Engineering \& Technology, Volume 38, No. 1, January, 2019 [p-ISSN: 0254-7821, e-ISSN: 2413-7219] 
system with prohibited operated zones and transmission loss are considered. Data of this system is available in [14]. Numbers of moths are 30 for this test system with 1000 iterations and 50 trails

Optimal generation and minimum fuel cost of 15-units test system obtained from proposed technique is shown in the Table 3. Total generation found to be 2656.770 MW in which 26.770 MW are transmission losses and best minimum fuel cost found through proposed technique is 32548.005 US\$/hr. Results are compared with different techniques reported in the literature to validate the effectiveness of proposed technique and showed in Table 4. Fig. 2 is showing the converging behavior of MFO-SQP.

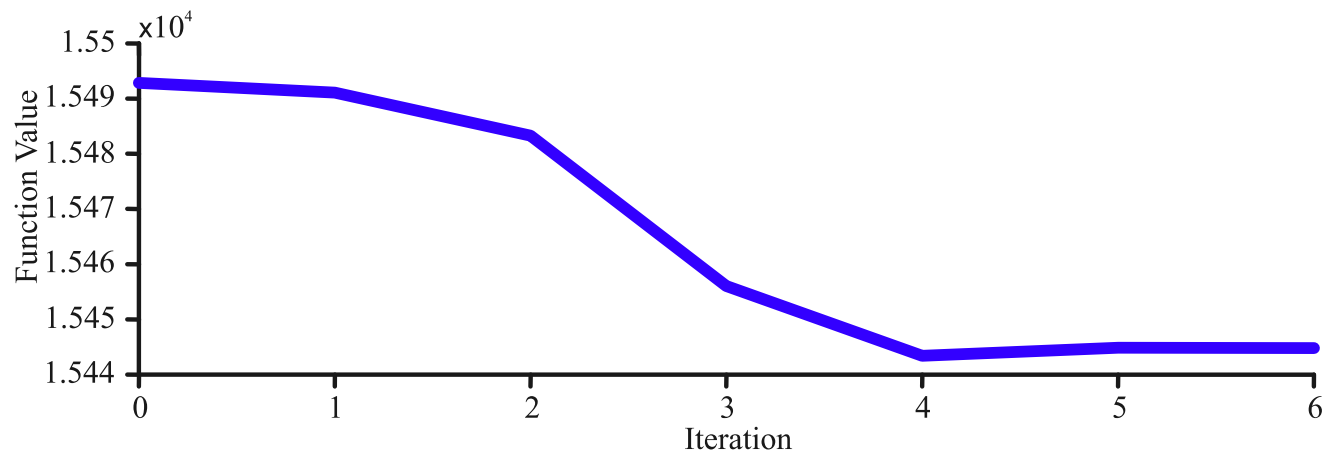

FIG. 1. CONVERGENCE CURVE FOR 6 UNITS TEST SYSTEM

TABLE 3. OPTIMAL GENERATION AND COST (15 UNITS TEST SYSTEM)

\begin{tabular}{|c|c|c|c|c|}
\hline Units & $\begin{array}{c}\mathrm{P}_{\mathrm{imin}} \\
(\mathrm{MW})\end{array}$ & $\begin{array}{c}P_{\text {imax }} \\
(\mathrm{MW})\end{array}$ & $\begin{array}{c}\text { Generation } \\
\text { (MW) }\end{array}$ & $\begin{array}{c}\text { Fuel Cost } \\
\text { (US } \$ / h r)\end{array}$ \\
\hline 1 & 150 & 455 & 455.000 & 5328.400 \\
\hline 2 & 150 & 455 & 455.000 & 5252.886 \\
\hline 3 & 20 & 130 & 130.000 & 1537.029 \\
\hline 4 & 20 & 130 & 130.000 & 1537.029 \\
\hline 5 & 150 & 470 & 231.786 & 2882.588 \\
\hline 6 & 135 & 460 & 460.000 & 5339.692 \\
\hline 7 & 135 & 465 & 465.000 & 5183.706 \\
\hline 8 & 60 & 300 & 60.000 & 900.217 \\
\hline 9 & 25 & 162 & 25.000 & 453.504 \\
\hline 10 & 25 & 160 & 35.622 & 557.682 \\
\hline 11 & 20 & 80 & 74.362 & 964.322 \\
\hline 12 & 20 & 80 & 80.000 & 1057.283 \\
\hline 13 & 25 & 85 & 25.000 & 552.732 \\
\hline 14 & 15 & 55 & 15.000 & 490.934 \\
\hline 15 & 15 & 55 & 15.000 & 510.001 \\
\hline \multicolumn{3}{|c|}{ Total } & 2656.770 & 32548.005 \\
\hline
\end{tabular}

Mehran University Research Journal of Engineering \& Technology, Volume 38, No. 1, January, 2019 [p-ISSN: 0254-7821, e-ISSN: 2413-7219] 


\subsection{Test System-3}

In this case, proposed algorithm has been implemented on large test system with 40 units. Transmission loss and valve point loading effect are considered as constraints.
Data of test system with generator limits capacity, valve point loading effect and transmission loss are available in [31] with Load demand of 10500 MW. Numbers of moths are 30 for this test system with 1000 iterations and 50 trails.

TABLE 4. COMPARISON OF 15 UNITS TEST SYSTEM

\begin{tabular}{|c|c|}
\hline Technique & $\begin{array}{l}\text { Best Cos } \\
\text { (US\$/hr) }\end{array}$ \\
\hline SQPSO [24] & 32704.860 \\
\hline IPSO [25] & 32704.450 \\
\hline DSPSO-TSA [26] & 32715.060 \\
\hline GAAPI [18] & 32732.950 \\
\hline IAEDP [27] & 32698.201 \\
\hline SLTLBO [28] & 32661.006 \\
\hline PSO [17] & 32858.540 \\
\hline ACHS [29] & 32706.570 \\
\hline $\mathrm{DE}[16]$ & 32609.850 \\
\hline $\mathrm{CSO}[30]$ & 32588.920 \\
\hline KHA-1 [19] & 32586.370 \\
\hline KHA-2 [19] & 32569.800 \\
\hline KHA-3 [19] & 32564.380 \\
\hline GWO [12] & 32555.000 \\
\hline NAPSO [19] & 32548.585 \\
\hline MFO [23] & 32849.331 \\
\hline Proposed MFO-SQP & 32548.005 \\
\hline
\end{tabular}

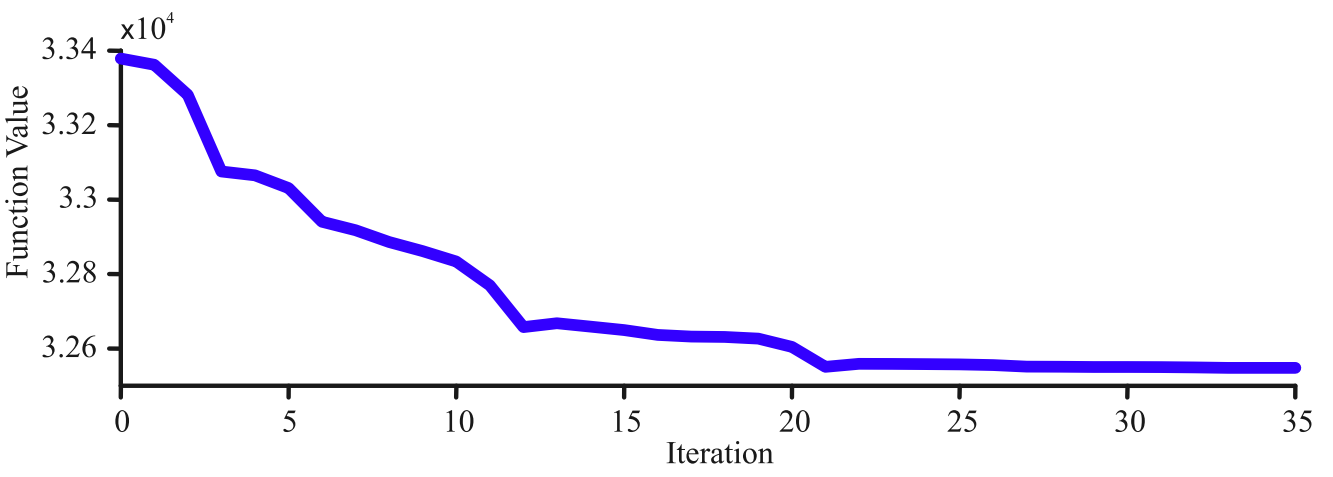

FIG. 2. CONVERGENCE CURVE FOR 15 UNITS TEST SYSTEM 
Optimal generation and minimum fuel cost of 40-units (with loss) test system obtained from proposed technique is shown in the Table 5. Total generation found to be 11470.227 MW with transmission loss 970.227 MW and best minimum fuel cost found through proposed technique is 136376.531 US\$/hr. Results are compared with different techniques available in the literature to check the effectiveness of proposed technique and showed in Table 6.

TABLE 5. OPTIMAL GENERATION AND COST (40 UNITS TEST SYSTEM)

\begin{tabular}{|c|c|c|c|c|}
\hline Units & $\begin{array}{l}\mathrm{P}_{\mathrm{i} \text {,min }} \\
\text { (MW) }\end{array}$ & $\begin{array}{c}\mathrm{P}_{\text {imax }} \\
\text { (MW) }\end{array}$ & $\begin{array}{l}\text { Generation } \\
\text { (MW) }\end{array}$ & $\begin{array}{c}\text { Fuel Cost } \\
\text { (US\$/hr) }\end{array}$ \\
\hline 1 & 36 & 114 & 110.861 & 926.116 \\
\hline 2 & 36 & 114 & 110.843 & 925.816 \\
\hline 3 & 60 & 120 & 120.000 & 1544.653 \\
\hline 4 & 80 & 190 & 179.733 & 2143.550 \\
\hline 5 & 47 & 97 & 87.800 & 706.502 \\
\hline 6 & 68 & 140 & 140.000 & 1596.464 \\
\hline 7 & 110 & 300 & 300.000 & 3297.424 \\
\hline 8 & 135 & 300 & 284.600 & 2779.843 \\
\hline 9 & 135 & 300 & 284.600 & 2798.237 \\
\hline 10 & 130 & 300 & 279.600 & 4802.629 \\
\hline 11 & 94 & 375 & 243.600 & 4083.249 \\
\hline 12 & 94 & 375 & 168.800 & 2977.459 \\
\hline 13 & 125 & 500 & 484.039 & 7950.266 \\
\hline 14 & 125 & 500 & 484.039 & 7801.195 \\
\hline 15 & 125 & 500 & 484.039 & 7816.058 \\
\hline 16 & 125 & 500 & 484.039 & 7816.058 \\
\hline 17 & 220 & 500 & 489.279 & 5296.711 \\
\hline 18 & 220 & 550 & 399.520 & 4325.477 \\
\hline 19 & 242 & 550 & 511.279 & 5540.929 \\
\hline 20 & 242 & 550 & 511.280 & 5540.923 \\
\hline 21 & 254 & 550 & 523.280 & 5071.302 \\
\hline 22 & 254 & 550 & 523.279 & 5071.290 \\
\hline 23 & 254 & 550 & 523.279 & 5057.223 \\
\hline 24 & 254 & 550 & 523.279 & 5057.223 \\
\hline 25 & 254 & 550 & 523.280 & 5275.101 \\
\hline 26 & 254 & 550 & 523.280 & 5275.101 \\
\hline 27 & 10 & 150 & 10.000 & 1140.524 \\
\hline 28 & 10 & 150 & 10.000 & 1140.524 \\
\hline \multicolumn{3}{|c|}{ Total } & 11470.227 & 136376.587 \\
\hline
\end{tabular}


Fig. 3 gives the convergence behavior of MFO-SQP for 40-unit test system (with loss) on 1000 iterations. Stopping criteria of proposed technique was maximum iterations. It is obvious that proposed technique converges to optimal solution before reaching the maximum iterations.

\section{CONCLUSION}

This paper presented a new hybrid MFO-SQP algorithm. Hybrid algorithms are the combination of two or more algorithms. These algorithms are efficient for optimization because they use the best feature of combined algorithms.

TABLE 6. COMPARISON OF 40 UNITS TEST SYSTEM (WITH LOSS)

\begin{tabular}{|c|c|}
\hline Technique & $\begin{array}{l}\text { Best Cos } \\
\text { (US\$ } \$ \text { hr) }\end{array}$ \\
\hline SDE [1] & 138157.460 \\
\hline GAAPI [18] & 139864.960 \\
\hline KHA-1 [19] & 136702.583 \\
\hline KHA-2 [19] & 136692.654 \\
\hline KHA-3 [19] & 136683.654 \\
\hline KHA-4 [19] & 136670.370 \\
\hline GWO [12] & 136446.850 \\
\hline ORCCRO [32] & 136855.190 \\
\hline DE/BBO [32] & 136950.770 \\
\hline $\mathrm{BBO}[32]$ & 137026.820 \\
\hline HGWO [32] & 136681.000 \\
\hline Proposed MFO-SQP & 136376.531 \\
\hline
\end{tabular}

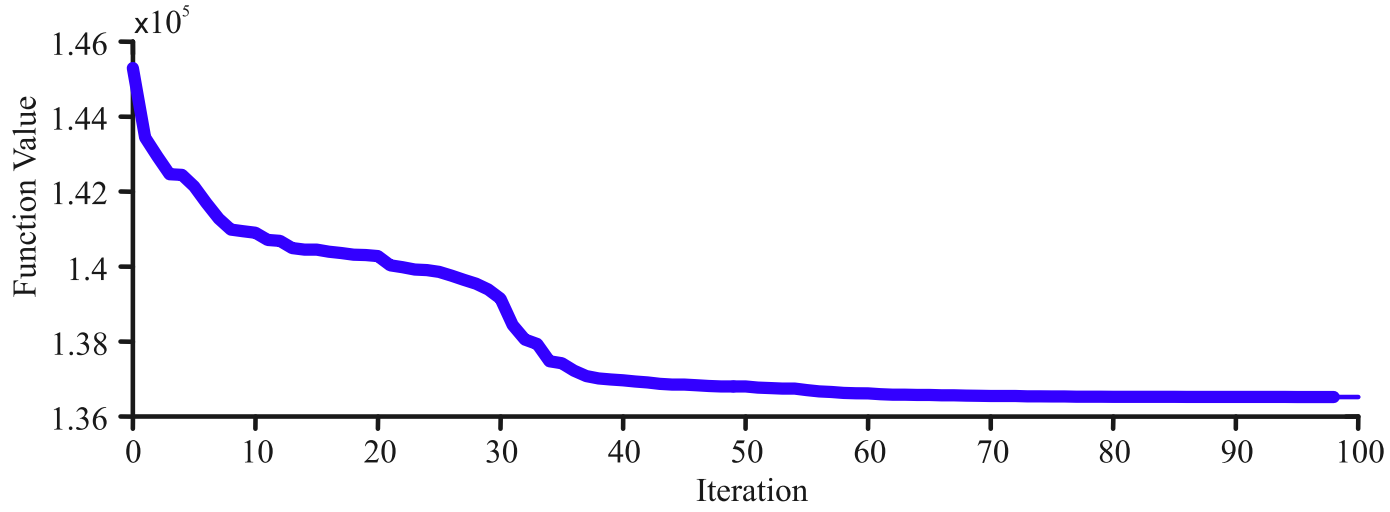

FIG. 3. CONVERGENCE CURVE FOR 40 UNITS TEST SYSTEM 
For this research work, MFO is stochastic searching algorithm minimized by random search and SQP is being definite in nature which refines the local search in vicinity of local minima. MFO do not need starting point but has less global optimum searching ability and SQP needs starting point to search global optimum point. So, the best features of both algorithms are used here to get the optimum point.

Proposed algorithm is successfully implemented on three different convex and non-convex test systems $(6,15$ and 40) with transmission losses, prohibited operated zones, generator capacity limits, valve point loading effect and real power balance as constraints. MFO-SQP proves superior in terms of minimizing fuel cost of thermal power generation.

The statistical analysis proves that proposed research saves 1.169 US $\$ / \mathrm{h}$ for 6 units test system, 0.580876 US\$/ $\mathrm{h}$ for 15 units test system and 70.319 US $\$$ hr for 40 units test system which shows $0.008,0.002$ and $0.052 \%$ improvements in above three test systems respectively. Another feature of this algorithm is that it does not suffer from the curse of dimensionality. The proposed MFOSPQ algorithm has been compared with other techniques in literature and it is found to be efficient in terms of cost reduction and convergence

\section{ACKNOWLEDGEMENT}

The authors wish to acknowledge the support from Ph.D. and M.Sc. Graduates, Department of of Electrical Engineering, University of Engineering \& Technology, Taxila, Pakistan.

\section{REFERENCES}

[1] . 
[11] Mirjalili, S., "Moth-Flame Optimization Algorithm: A Novel Nature-Inspired Heuristic Paradigm", KnowledgeBased Systems, Volume 89, pp. 228-249, 2015.

[12] Pradhan, M., Roy, P.K., and Pal, T., "Grey Wolf Optimization Applied to Economic Load Dispatch Problems", International Journal of Electrical Power \& Energy Systems, Volume 83, pp. 325-334, 2016.

[13] Victoire, T.A.A., and Jeyakumar, A.E., "Hybrid PSOSQP for Economic Dispatch with Valve-Point Effect", Electric Power Systems Research, Volume 71, No. 1, pp. 51-59, 2004.

[14] Gaing, Z.-L., "Particle Swarm Optimization to Solving the Economic Dispatch Considering the Generator Constraints", IEEE Transactions on Power Systems, Volume 18, No. 3, pp. 1187-1195, 2003.

[15] Pothiya, S., Ngamroo, I., and Kongprawechnon, W., "Application of Multiple Tabu Search Algorithm to Solve Dynamic Economic Dispatch Considering Generator Constraints", Energy Conversion and Management, Volume 49, No. 4, pp. 506-516, 2008.

[16] Noman, N., and Iba, H., "Differential Evolution for Economic Load Dispatch Problems", Electric Power Systems Research, Volume 78, No. 8, pp. 1322-1331, 2008 .

[17] Tiwari, S., Kumar, A., Chaurasia, G., and Sirohi, G., "Economic Load Dispatch Using Particle Swarm Optimization", International Journal of Application or Innovation in Engineering and Management, Volume 2, No. 4, pp. 476-485, 2013.

[18] Ciornei, I., and Kyriakides, E., "A GA-API Solution for the Economic Dispatch of Generation in Power System Operation", IEEE Transactions on Power Systems, Volume 27, No. 1, pp. 233-242, 2012.

[19] Mandal, B., Roy, P.K., and Mandal, S., "Economic Load Dispatch Using Krill Herd Algorithm", International Journal of Electrical Power \& Energy Systems, Volume 57, pp. 1-10, 2014.

[20] Saka, M., Tezcan, S.S., Eke, I., and Taplamacioglu, M.C., "Economic Load Dispatch Using Vortex Search Algorithm", Proceedings of IEEE 4th International Conference on Electrical and Electronic Engineering, pp. 77-81, 2017.
[21] Secui, D.C., "A New Modified Artificial Bee Colony Algorithm for the Economic Dispatch Problem", Energy Conversion and Management, Volume 89, pp. 43-62, 2015.

[22] Adarsh, B., Raghunathan, T., Jayabarathi, T., and Yang, X.-S., "Economic Dispatch Using Chaotic Bat Algorithm”, Energy, Volume 96, pp. 666-675, 2016.

[23] Trivedi, I., Kumar, A. Ranpariya, A.H., and Jangir, P., "Economic Load Dispatch Problem with Ramp Rate Limits and Prohibited Operating Zones Solve Using Levy Flight Moth-Flame Optimizer",Proceedings of IEEE International Conference on Energy Efficient Technologies for Sustainabilitypp. 442-447, 2016.

[24] Hosseinnezhad, V., Rafiee, M., Ahmadian, M., and Ameli, M.T., "Species-Based Quantum Particle Swarm Optimization for Economic Load Dispatch", International Journal of Electrical Power \& Energy Systems, Volume 63, pp. 311-322, 2014.

[25] Kim, M.J., Song, H.-Y., Park, J.-B., Roh, J.-H., Lee, S.U., and Son, S.-Y., "An Improved Mean-Variance Optimization for Nonconvex Economic Dispatch Problems", Journal of Electrical Engineering and Technology, Volume 8, No. 1, pp. 80-89, 2013.

[26] Khamsawang, S.,and Jiriwibhakorn, S., "DSPSO-TSA for Economic Dispatch Problem with Nonsmooth and Noncontinuous Cost Functions”, Energy Conversion and Management, Volume 51, No. 2, pp. 365-375, 2010.

[27] Aragón, V.S., Esquivel, S.C., and Coello, C.C., “An Immune Algorithm with Power Redistribution for Solving Economic Dispatch Problems", Information Sciences, Volume 295, pp. 609-632, 2015.

[28] Prakash, T., Singh, V., Singh, S.P., and Mohanty, S., "Economic Load Dispatch Problem: Quasi-Oppositional Self-Learning TLBO Algorithm", Energy Systems, pp. 1-24, 2017. 
[29] Niu, Q., Zhang, H., Wang, X., Li, K., and Irwin, G.W., “A Hybrid Harmony Search with Arithmetic Crossover Operation for Economic Dispatch", International Journal of Electrical Power \&Energy Systems, Volume 62, pp. 237-257, 2014.

[30] Selvakumar, A.I., and Thanushkodi, K., "Optimization Using Civilized Swarm: Solution to Economic Dispatch with Multiple Minima”, Electric Power Systems Research, Volume 79, No. 1, pp. 8-16, 2009.
[31] Sinha, N., Chakrabarti, R., and Chattopadhyay, P., "Evolutionary Programming Techniques for Economic Load Dispatch", IEEE Transactions on Evolutionary Computation, Volume 7, No. 1, pp. 83-94, 2003.

[32] Jayabarathi, J., Raghunathan, T., Adarsh, B., and Suganthan, P.N., "Economic Dispatch Using Hybrid Grey Wolf Optimizer", Energy, Volume 111, pp. 630-641, 2016. 